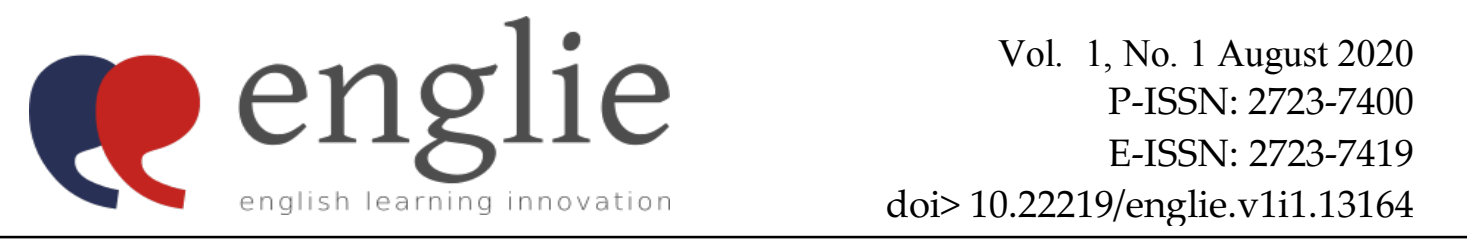

\title{
Identifying EFL Learners' Uptakes in Response to Corrective Feedback
}

\author{
Eka Listianing Rahayu \\ Politeknik Negeri Malang \\ ekarahayu@polinema.ac.id
}

\begin{abstract}
Corrective feedback is often intended to draw learners' attention to repair linguistic forms when performing communicative activities. While researchers argue that feedback plays a role in L2 development, some teachers doubt what type of feedback is suitable for certain errors. Another issue is whether or not the given feedback is incorporated or responded by the learners. This current study focuses on two corrective feedback, namely recast and elicitation. It aims to identify which feedback elicits more uptakes from the learners. Besides, since uptakes may come in different forms, the study investigates the types of uptakes generated by learners in response to the given feedback. By involving EFL learners in a communicative task and analysing the feedback and uptake that appeared during the task, it was found that recast has elicited more uptake than elicitation. The uptake yielded includes repetition, acknowledgment, and incorporation, with repetition showing the highest frequency.
\end{abstract}

Keywords: corrective feedback, EFL learners, uptake

\section{INTRODUCTION}

The limited knowledge of the target language possessed by language learners can lead to errors in their language production. Learners may perform an error repeatedly without being aware of it if they do not receive feedback. In this case, the teacher's corrective feedback can have a significant effect on their L2 development. The feedback given may vary in terms of the types and purposes. For example, a teacher may provide feedback intentionally to correct the ill-formed utterances produced by the learners or merely to clarify meanings. Some feedback can elicit positive responses from the learners or are internalised during the learning process and lead to immediate repairs. In this case, learners benefit from the feedback and, as a result, improve their language proficiency as they are fully aware of the feedback and respond to it accordingly. However, not all feedback is internalised or understood by the learners. That being said, while some feedback generates responses, others may pass unnoticed or result in no response, hereinafter referred to as uptake or no uptake.

Corrective feedback is often defined as a focus on form, intended to draw learners' attention to linguistic forms when performing communicative activities (Morris, 2005). In response to feedback, uptake may occur. Lyster \& Ranta (1997, p.49) define uptake as "a student's utterance that immediately follows the teacher's feedback, and that 
constitutes a reaction in some way to the teacher's intention to draw attention to some aspect." Following this definition, uptake is regarded as students' reaction or response to the given feedback, regardless of the quality. It may also refer to the students' interpretation of the feedback they have received, which may be correct or incorrect. Since this is a personal interpretation, the quality of uptake can be influenced by the learners' ability or language level. On the one hand, a learner with a higher language level may perform a better or improved uptake. On the other hand, a lower-level learner may generate limited or incorrect uptake.

Despite the fact that some feedback leads to uptake and provide opportunities for language learners to generate modified outcomes, correcting the learners' errors seems to be problematic. Allen et al. (1990) argue that the absence of feedback decreases the learners' opportunities to make links between forms and functions in the target language. At the same time, correcting the learners' errors may break the flow of communication. This situation may be the underlying reason for some teachers to provide the necessary feedback for the learners. Indeed, corrective feedback is a complex matter (Ellis, 2009). While it is often addressed as a teacher's support to assist the students in performing the task better, some issues arise whether or not it brings a significant impact on L2 acquisition.

Therefore, to see whether corrective feedback brings advantage to the learner's language development, it is important to look back on some previous research in this area. Large numbers of research have been done previously to investigate the effect of feedback on learner's second language development, either in the context of Native speaker (NS) and Non-native speaker (NNS) interactions (Ware \& O'Dowd, 2008; Sauro, 2009) or NNS-NNS interaction (Morris, 2005; Jang, 2010; Asari, 2015). These previous studies have found that most feedback leads to uptake.

Asari (2015) observed NNS-NNS interaction in L2 class and reported that providing interrupted feedback worked effectively and helped build students' confidence and sense of accomplishment as they were given a chance to make repairs and achieve higher accuracy in their L2 learning.

Jafarigohar and Gharbavi (2014) conducted a study on Iranian English learners by exploring different effects of different types of feedback (e.g., recast vs. elicitation). It was found that elicitation was more effective than recast because "in recast, error correction does not call on higher-order processing on the part of learners" (p.701). This is consistent with Lyster (1998a), who mentioned that recasts often go unnoticed due to their implicit nature. Therefore, learners are often unaware of the correction.

Zhuo (2010) also found that the types of feedback influence the effectiveness of the feedback. This study reported that explicit feedback was more effective in eliciting students' responses than implicit feedback. However, Lyster, Saito, and Sato (2013) argue that a wide range of feedback is necessary to familiarize students with various feedbacks as different content or materials may need different types of feedback. Also, learners with varying abilities of language may internalise feedback differently. 
In terms of students' response, or commonly known as uptake, Egi (2010) confirmed that learner uptake is indeed a signal that the learners understand the primary purpose of the feedback, that is, to highlight learners' errors and encourage them to correct the erroneous output.

This current study is undertaken in the context of NNS-NNS interaction and focused on two types of feedback, namely recast and elicitation. These types of feedback were chosen because, in the previous study, recast was the most frequent type of feedback used in the classroom (Lyser \& Ranta, 1997; Morris, 2005; Jafarigohar and Gharbavi, 2014). In these previous studies, it was found that although it occurred most frequently compared to other types of feedback, recast did not seem to be the most successful type of feedback in eliciting uptake. In contrast, elicitation yielded the most uptake, although it occurred less frequently than the recast. Another research on corrective feedback done by Sauro (2009) found that recast frequently occurred in the learner's interaction. However, it was less effective for immediate improvements in the target knowledge compared to metalinguistic feedback.

Considering the negative correlation between the high frequency of recast and its low frequency of uptake in the previous research, this study aims to compare recast to elicitation in terms of its uptake and see if similar results will be achieved. Therefore, the research questions are formulated as follows:

1. Which corrective feedback results in more uptakes from learners?

2. What type of uptake generated by learners in response to the given feedback?

Through this study, it is expected that there is a better understanding of the possible incorporation of the corrective feedback in learner's uptake that may bring positive results in the learner's second language improvement.

\section{METHOD}

This is qualitative research using the process of observation and record keeping. To accompany the description, quantitative data were also provided to present the learners' frequency of uptakes. The research was conducted in a private EFL course, which consisted of four students and one teacher. The participants were 4 non-native speakers of English consisting of 2 females and 2 males with Indonesian language background who aged between 23-28 years old. Three participants were at an intermediate level of English while another was at the beginner level, as indicated in their IELTS or TOEFL score. The data was collected from the conversation task between the researcher and each participant. The conversation was recorded, then transcribed for further analysis. During the conversation, two different types of feedback were provided, namely recast and elicitation for erroneous utterances to see which type of feedback elicits more uptake and what kind of uptake is generated by the learners. From the transcription, all feedback that appeared in response to the learner's errors was classified into recast and elicitation, then followed by analysing if the feedback resulted in uptake. Finally, the uptakes generated by the learners were classified into different types, which will be explained in more detail in the next section.

englie: English Learning Innovation I,(1) 36-43 


\section{RESULTS AND DISCUSSION}

The corrective feedback identified in this study was based on Lyster \& Ranta (1997). Below are some instances of both recast and elicitation provided during the research and the uptakes generated by the learners in response to the given feedback. The number of both feedback and uptakes are presented in the tables that follow.

\section{A. Corrective Feedback}

\section{The corrective feedback analysed in this study are twofold:}

\section{Recast}

This feedback involves the reformulation of all or part of a learner's utterance, minus the error. Chaudron (1977) also mentioned that recast is a repetition with change and emphasis.

S2: she's handling his hand with the woman (ERROR)

\section{Elicitation}

$R$ : she's holding the woman's hand (RECAST)

The elicitation is used to elicit the correct form from the student. Such elicitation can be provided in the form of questions or filling in the blank.

S2: They use suits (ERROR)

$R$ : What do they wear? (ELICITATION)

S4: He is go to office (ERROR)

$R$ : He goes to........ (ELICITATION)

\section{B. Uptake}

Three types of uptakes were identified in this study, namely repetition, incorporation, and acknowledgment.

1. Repetition refers to a learner's repetition of the feedback that provides the correct form.

S4: He is like ice cream (ERROR)

$R$ : He likes ice cream (RECAST)

S4: He like is cream (REPETITION)

2. Incorporation refers to a student's repetition of the correct form provided by the teacher, which is then incorporated into a longer utterance produced by the student.

S4: This man buy a ticket. (ERROR)

R: What does he buy? He buys what? (ELICITATION)

S4: He buys a ticket in the train station (INCORPORATION)

3. Acknowledgment generally refers to a simple "yes" or another short utterance in response to the feedback as if to say, "Yes, that is indeed what I meant to say (but you've just said it much better!")

S3: The man seems like to buy a ticket (ERROR)

R: He buys a ticket? (RECAST)

S3: Yeah (ACKNOWLEDGEMENT) 
Note:

R: Researcher

S1: Speaker 1

S2: Speaker 2

S3: Speaker 3

S4: Speaker 4

The frequency of the corrective feedback (both recast and elicitation) is shown in Table 1 below.

Table 1: Frequency of feedback

\begin{tabular}{lll} 
Speaker & Recast & Elicitation \\
\hline 1 & 3 & 1 \\
2 & 5 & 5 \\
3 & 3 & 0 \\
4 & 5 & 9 \\
Total & 16 & 15 \\
\hline
\end{tabular}

Table 1 shows the frequency of recast and elicitation in each conversation. This table reveals that the frequency of recast is slightly higher than the frequency of elicitation; speaker 4 received the highest feedback, while speaker 3 received the least feedback. In this case, only recast is provided during the conversation with speaker 3 .

Table 2: Recast and uptake

\begin{tabular}{lllll} 
Speaker & Recast & Repetition & Incorporatior & Acknowledgment \\
\hline 1 & Recast & 1 & 1 & 0 \\
2 & Recast & 4 & 1 & 0 \\
3 & Recast & 1 & 0 & 2 \\
4 & Recast & 1 & 0 & 1 \\
\multicolumn{2}{l}{ Total uptake } & $\mathbf{7}$ & $\mathbf{2}$ & $\mathbf{3}$ \\
\hline
\end{tabular}

Table 3: Elicitation and uptake

\begin{tabular}{lllll} 
Speaker & Elicitation & Repetition & Incorporation & Acknowledgment \\
\hline 1 & Elicitation & 0 & 0 & 0 \\
2 & Elicitation & 0 & 0 & 0 \\
3 & Elicitation & 0 & 0 & 0 \\
$\mathrm{~T}^{4}$ & Elicitation & 3 & 4 & 0 \\
\multicolumn{1}{l}{ Total uptake } & $\mathbf{3}$ & $\mathbf{4}$ & $\mathbf{0}$ \\
\hline
\end{tabular}

englie: English Learning Innovation I,(1) 36-43 
Table 2 and Table 3 show the number of uptakes generated in response to recast and elicitation, respectively. The tables indicate that recast yields more uptake compared to elicitation (12:7). It can be seen from these tables that the three different types of uptake occurred in response to recast. On the other hand, the uptake for elicitation only includes repetition and incorporation, and none of the acknowledgment is produced. In this case, only speaker 4 generates uptake, while other speakers generate no uptake in response to elicitation.

The different numbers in the frequency of feedback and uptake in Tables 1 and 2 suggest that some feedback results in either no uptake or the same error (no repairs of the erroneous utterances).

Other types of feedback also occurred naturally during the conversation task, such as clarification request, metalinguistic feedback, probably due to the interactive nature of the conversations. However, they were not analysed since this study only focused on recast and elicitation.

The interpretation of the results permits the answer to the following research questions.

\section{RQ1: What type of feedback elicits more uptake?}

The recast elicited more uptake than the elicitation did. This result is in contrast to the previous research, which found that recast elicited less uptake than other feedback, including the elicitation (Lyster and Ranta, 1997; Jafarigohar and Gharbavi, 2014; Ito, 2015). Nevertheless, in terms of the frequency of recast, similar results as the previous study were achieved, indicating that recast occured more frequently than other types of feedback.

\section{RQ2: What type of uptake occurs as a result of feedback?}

Three different uptakes, namely repetition, incorporation, and acknowledgment, occured in response to the feedback, with repetition and acknowledgment being generated more frequently in response to the recast. In contrast, incorporation was produced more in response to the elicitation. Meanwhile, none of the acknowledgment was produced in accordance with the elicitation.

The findings reveal that speaker 3 received the least feedback, mainly because of the limited number of sentences produced by this speaker. On the other hand, speaker 4 received the most feedback due to the large numbers of errors during the conversation. In this study, speaker 3 was less active compared to other speakers, and speaker 4 was the least able learner among others.

\section{Implications for Language Teaching and Further Research}

During the conversation, the researchers made an attempt to provide repetitive feedback to encourage the learners to use the feedback in the subsequent talks. This attempt was successful in eliciting the application of the corrected form by the more able learners but had no effect on the less able learner. The feedback sometimes overwhelmed the less able learner and led to more errors. Thus, it is suggested that 
repetitive feedback be provided in separate activities for the less able learners to give time for those learners to internalise the new knowledge in the target form.

In the teaching process, it is not always easy to limit to only a specific type of feedback because it depends on the flow of the conversation and the types of errors occurred. Although the findings in these current and previous studies suggest that the uptake often occurs as a result of feedback, this does not necessarily reflect a development in L2 knowledge since the result may be temporary at the time of the interaction. Therefore, a further study with a larger number of participants that includes a pre- and post-test to compare the learners' language proficiency before and after the feedback is necessary.

\section{CONCLUSION}

The findings of this study show that different type of feedback elicits a different type of uptake. Although not all the feedback resulted in uptake, giving feedback to correct the learners' errors, regardless of the type, may contribute to the improvement of the learners' language knowledge since there are opportunities for such incorporation, repetition, and acknowledgment to occur in response to the feedback.

\section{REFERENCES}

Asari, Y. (2015). How to effectively provide recast in a foreign language classroom. Dialogue, 13, 1-9.

Baleghizadeh, S., \& Abdi, H. (2010). Recast and Its Impact on Second Language Acquisition. International Journal of Language Studies, 4(4).

Egi, T. (2010). Uptake, modified output, and learner perceptions of recasts: Learner responses as language awareness. The modern language journal, 94(1), 1-21.

Ellis, R. (2009). Corrective feedback and teacher development. L2 Journal, 1(1).

Gloria, S. O. T. O., Clarke, M. T., Nelson, K., Starowicz, R., \& Savaldi-Harussi, G. (2020). Recast type, repair, and acquisition in AAC mediated interaction. Journal of child language, 47(1), 250-264.

Ito, K. (2015). Recast and elicitation: The effectiveness of corrective feedback on Japanese language learners.

Jafarigohar, M., \& Gharbavi, A. (2014). Recast or Prompt: Which One Does the Trick?. Procedia-Social and Behavioral Sciences, 98, 695-703.

Jang, S. S. (2010). The interaction of mediating factors in recast efficacy on noticing and L2 development. 응용언어학, 26(4), 49-79.

Lyster, R. (1998a). Negotiation of form, recasts, and explicit correction in relation to error types and learner repair in immersion classrooms. Language Learning, 48, 183- 218.

Lyster, R., \& Ranta, L. (1997). Corrective feedback and learner uptake: Negotiation of form in communicative classrooms. Studies in Second Language Acquisition, 19(1), 37-66.

Lyster, R., Saito, K., \& Sato, M. (2013). Oral corrective feedback in second language classrooms. Language teaching, 46(1), 1-40.

Morris, F. (2005). Child-to-child interaction and corrective feedback in a computermediated L2 class. Language Learning \& Technology, 9(1), 29-45. 
Nicholas, H., Lightbown, P. M., \& Spada, N. (2001). Recasts as feedback to language learners. Language learning, 51(4), 719-758.

Panova, I., \& Lyster, R. (2002). Patterns of corrective feedback and uptake in an adult ESL classroom. Tesol Quarterly, 36(4), 573-595.

Pei-zhi, Y. (2012). Re-examing the Definitions of "Recast" in L2 Research. Foreign Language Research, (6), 32.

Rezaei, S., \& Derakhshan, A. (2011). Investigating recast and metalinguistic feedback in task-based grammar instruction. Journal of Language Teaching and Research, 2(3), 655.

Sepehrinia, S., Zarea, A., Moghaddam, M. S., \& Nasiri, M. (2011). From perceptions to practice: Factors affecting recast. International Journal of English Linguistics, 1(2), 18.

Sheen, Y. (2004). Corrective feedback and learner uptake in communicative classrooms across instructional settings. Language teaching research, 8(3), 263-300.

Sheen, Y., \& Ellis, R. (2011). Corrective feedback in language teaching. Handbook of research in second language teaching and learning, 2, 593-610.

Ware, P. D., \& O'Dowd, R. (2008). Peer feedback on language form in telecollaboration. Language Learning\& Technology, 12(1), 43-63.

Woodward, S. W. (1997). Fun with grammar: communicative activities for the Azar Grammar series. New Jersey: Prentice-Hall Regents.

Zhuo, C. (2010). Explicit Recast, Implicit Recast, and the Acquisition of English Noun Plural: A Comparative Study. Chinese Journal of Applied Linguistics (Foreign Language Teaching \& Research Press), 33(6). 